\title{
Differential expression of ryanodine receptor in the developing rat cochlea
}

\author{
Y. Liang, L. Huang, J. Yang \\ Department of Otorhinolaryngology-Head \& Neck Surgery, Xinhua Hospital, Shanghai Jiaotong University \\ School of Medicine, Shanghai Ear Institute, Shanghai, China
}

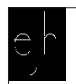

(C2009 European Journal of Histochemistry

Ryanodine receptors (RyRs) are one of the intracellular calcium channels involved in regulation of intracellular free calcium concentration $\left(\left[\mathrm{Ca}^{2+}\right]_{i}\right)$. The immunolocalization of RyRs was investigated in the developing rat cochlea at different postnatal days (PND). The change of $\left[\mathrm{Ca}^{2+}\right]_{\text {i }}$ in isolated outer hair cells (OHCs) was determined. Morphological results showed low expression of RyRs in the Kolliker's organ from the PND 5 group. RyR expression in inner hair cells (IHCS) increased as the rats aged, and was mature after PND 14. RyRs in OHCs were expressed near the synaptic area of afferent and efferent nerves. RyRs in supporting cells were expressed widely and strongly. The application of ACh, ryanodine $+\mathrm{ACh}$, and thapsigargin + ACh could induce a significant increase in $\left[\mathrm{Ca}^{2+}\right]_{i}$ in $\mathrm{OHCs}$ in the presence of extracellular calcium. This increase of $\left[\mathrm{Ca}^{2+}\right]$ induced by ACh was caused by not only the calcium influx through surface calcium channels, but also the calciuminduced calcium release (CICR) from intracellular RyR-sensitive calcium stores. Morphological and $\mathrm{Ca}$ imaging results suggested that RyRs expression is related to cochlear maturity, and may play an important role in its function.

Key words: ryanodine receptor, development of cochlea, $\mathrm{Ca}^{2+}$, calcium-induced calcium release.

Correspondence: Jun Yang,

Department of Otorhinolaryngology-Head \& Neck Surgery, Xinhua Hospital, Shanghai Jiaotong University School of Medicine, Shanghai Ear Institute, Shanghai, 200092, China Tel.: +86.21.65790000.8432.

Fax: +86.21.65156489.

E-mail: yangjun_bioon@126.com

Y. Liang and L. Huang are co-first author.

Paper accepted on October 18, 2009

European Journal of Histochemistry 2009; vol. 53 issue 4 (October-December): 249-260
0 hanges in intracellular $\mathrm{Ca}^{2+}$ concentration $\left(\left[\mathrm{Ca}^{2+}\right]_{i}\right)$ play an important role in cellular communication. The intracellular $\mathrm{Ca}^{2+}$ concentration is mainly mediated by two pathways: calcium entry via membrane calcium channels and calcium release from intracellular stores. The latter is mediated by 1, 4, 5-inositol triphosphate receptors (IP3R) and ryanodine receptors (RyRs). Mechanism of calcium release induced by RyRs has been believed to be calcium-induced calcium release (CICR) (Chakraborti et al., 2007). In the mammalian auditory system, calcium released from intracellular calcium stores in inner hair cells (IHCs), outer hair cells (OHCs), Deiters' cells, and basal cells of stria vascularis plays an important role in the regulation of auditory transduction and electrochemical equilibrium of the cochlea (Bobbin, 2002; Marcotti et al., 2004). Neural transmitters, such as glutamate, ATP, acetylcholine (ACh), and substance $P$, can activate calcium signaling in spiral ganglia neurons, and then regulate the excitability of auditory neurons (Skinner et al., 2003). It has been reported that RyRs are widely expressed in the $\mathrm{IHCs}_{\mathrm{H}} \mathrm{OHCs}$, supporting cells in the organ of Corti's, and in spiral ganglia neurons (SGNs) (Lioudyno et al., 2004; Morton-Jones et al., 2006). In the OHCs, the RyRs are mainly expressed under the reticular lamina, where BK channels are also strongly expressed (Beurg et al., 2005). Other studies also revealed that RyRs expressed in the synaptic area at the bottom of OHCs and the adjacent Deiters' cells called as synaptoplasmic cistern (Lioudyno et al., 2004; Morton-Jones et al., 2006). Table 1 is a summary of location of RyR expression in previous references. The distance between synaptoplasmic cistern and postsynaptic membrane was only 30 $\mathrm{nm}$, implying the functional-coupling with the activation of the $\mathrm{ACh}$ receptors (Lioudyno et al., 
Table 1. Location of RyR expression in previous references.

\begin{tabular}{|c|c|}
\hline Reference & Localization of RyR expression \\
\hline Lioudyno et al., 2004 & $\begin{array}{l}\text { OHCs and Deiters' cells (RyR1) } \\
\text { Synaptic pole of OHCs }\end{array}$ \\
\hline Morton-Jones et al., 2006 & $\begin{array}{l}\text { Adult rat cochlea (three types of RyR) } \\
\text { SGN cell bodies (RyR) }\end{array}$ \\
\hline Beurg et al., 2005 & $\begin{array}{l}\text { Deiters' cells, IHCs and lateral membrane side and } \\
\text { basal synaptic areas of OHCs (RyR1) }\end{array}$ \\
\hline Skinner et al., 2003 & $\begin{array}{l}\text { Reticular laminae and lateral cell wall of the OHCS } \\
\text { and vicinity of the SGNs' membrane (RyRs) }\end{array}$ \\
\hline
\end{tabular}

2004; Morton-Jones et al., 2006). Three subtypes of RyRs have been identified expressed in the cochlea. RyRI was observed in the synapses of OHCs using an SP6-RNA probe. RyR2 was mainly expressed in Corti's organ and the cytoplasm of IHCs. RyR3 was found in the axons of SGNs located in the inner spiral plexus and the terminal of outer spiral fiber innervating $\mathrm{OHCs}$ (Lioudyno et al., 2004; Morton-Jones et al., 2006). These distinct expression patterns suggest that RyRs mediated calcium signaling plays important roles in auditory function.

RyR-mediated $\mathrm{Ca}^{2+}$ release may be involved in auditory neurotransmission, sound transduction, cochlear electrochemical homeostasis, and development (Morton-Jones et al., 2006). However, the relationship between calcium-induced calcium release (CICR) mediated by RyRs and the development of auditory function is unclear. CICR has been proposed to be evoked by calcium release from intracellular RyR-sensitive stores (Fabiato, 1983). On the other hand, there were fewer studies on the development of the inner ear in rats. Development of the rat auditory system started from the embryonic period and extended to the postnatal period. The developmental stage of the primary auditory afferent pathway and the auditory central in the brainstem was nearly mature at PND 14 (Auestad et al., 2003; Lee et al., 2007). However, whether the RyR expression promotes the auditory system maturate in the development of rat is still unclear. In this study, the distribution and expression of RyRs in the developing rat cochlea was investigated by use of immunofluorescent stain and confocal microscopy. Calcium imaging identified that RyR-mediated $\mathrm{Ca}^{2+}$ release may play an important role in the cochlear maturity.

\section{Materials and Methods}

\section{Animals}

For the immunohistochemical experiment, thirty SD rats were divided into six groups according to their ages ( $P N D 1,5,10,14,28$, and 60). Twenty rats with a body weight of 250 to $300 \mathrm{~g}$ were used for calcium imaging. All animals were supplied by the Experimental Animal Center of Affiliated Xinhua Hospital, Shanghai Jiaotong University School of medicine. All adult animals or the fathers of infant animals had a normal pinna reflex. All experiments conformed to the Shanghai Animal Management Committee. The number of animals used and their suffering were minimized.

\section{Immunofluorescence}

Rats were quickly decapitated and the cochleae dissected. The fixed cochlea was kept at $4^{\circ} \mathrm{C}$ overnight, and then decalcified using 10\% EDTA for 1 to 10 days, according to the age of animal. The EDTA solution was changed every day. After decalcification, the cochlea was dehydrated in 15\% sucrose for 3 hours and 30\% sucrose overnight. The dehydrated cochleae were embedded in OCT media for 3 hours, frozen, and sectioned at a thickness of $10 \mu \mathrm{m}$ horizontally along the modiolus. The glass slides were pre-coated with poly-D-lysine to avoid detachment. The sections were stored at $-20^{\circ} \mathrm{C}$.

After air drying at room temperature, the sections were permeated at $37^{\circ} \mathrm{C}$ for 40 minutes with $0.1 \%$ triton $\mathrm{X}-100$, and then blocked at $37^{\circ} \mathrm{C}$ for 30 to 40 minutes with $10 \%$ goat serum. Mice anti-RyR antibody [1:200, Monoclonal Anti-Ryanodine Receptor (Clone 34C), Sigma, USA] was directly applied to the section after removal of serum (without washing). This monoclonal Anti-Ryanodine Receptor reacts strongly with ryanodine receptor-1 [expressed predominantly in skeletal muscle and areas of the brain (Olivares EB et al. 1991, Ouyang $Y$ et al. 1993)] and receptor-2 (expressed predominantly in the heart muscle and diffuse areas of the brain (Jorgensen A0 et al. 1993, Walton PD et al. 1991)). For the control group, PBS was used instead of primary antibody. The stained sections were stored at $4^{\circ} \mathrm{C}$ overnight, followed by the application of FITC-conjugated goat anti-mouse antibody at $37^{\circ} \mathrm{C}$ for 2 hours. The sections were then sealed with $50 \%$ glycerophosphate buffer, adhered with nail polish, and observed using a fluorescence microscope. 


\section{Confocal $\mathrm{Ca}^{2+}$ imaging}

The rats were decapitated and bilateral cochleae were isolated and stored in Hank's or DHank's solution. The cochlea was opened, followed by removal of the shell and cutting of the modiolus. The cochlea was incubated in $0.25 \%$ type-IV collagenase (Sigma, USA) solution for 20 minutes at room temperature. Then the basilar membrane was removed and made into a cell suspension.

After cell attachment, Fluo-3/AM was applied at a final concentration of $5 \mu \mathrm{M}$ for 30 to 50 minutes in the absence of light. Acetylcholine (ACh) (Sigma, USA) solution was made using Hank's or D-Hank's solution and according to the concentration of ACh applied on isolated outer hair cells $(\mathrm{OHC})$ in the previous report (Blanchet et al., 1996), the final concentration in Petri dishes was $100 \mu \mathrm{M}$. The final concentration of thapsigargin (Biomol, USA) and ryanodine (Biomol, USA) in Petri dishes were $30 \mathrm{nM}$ and $30 \mu \mathrm{M}$, respectively. There were 6 groups, and in each group five cells were observed, and the experiment was performed on $\mathrm{OHCs}$. ACh, Ryanodine+ACh, thapsigargin +ACh were applied to the OHCs in Hank's and DHank's solution, respectively. Under latter two circumstances, Ryanodine or thapsigargin was first applied, followed by ACh after 200 seconds. The Fluo-3/AM-labeled OHCs were observed under a laser scanning confocal microscope (Bio-Rad Radiance 2000, USA). Lasersharp 2000 was used to calculate the relative fluorescence intensity to indicate the relative $\left[\mathrm{Ca}^{2+}\right]_{\text {. }}$.

\section{Analysis of data}

Statistical analysis of the data was provided as mean \pm S.E.M. using Microsoft Excel 10.0, and statistical significance was established by the paired student t-test using SPSS software (SPSS Inc., USA). Significance for all values was set at $p<0.05$.

\section{Results}

\section{RyRs expression in different parts of the cochlea during cochlear development}

Due to differential expression of RyRs in different parts of the cochlea, it was shown by area in each age group, and in each group Figure $A$ is the negative control. Table 2 shows the differential expression of the RyR in the rat cochlea development. Kolliker's organ is a temporary structure in the development of the cochlea, and it will degenerate when rat grows. In the PND 1 group, low expression was found in the basilar part of Kolliker's organ (Figure 1B), where cells might differentiate into inner sulcus cells. No obvious expression was observed in the main part of Kolliker's organ in the PND 1 group. The RyRs expression of Kolliker's organ in the PND 5 group was similar to that in the PND 1 group and very low expression in the main part (Figure 2B). In Corti's organ, significant temporal differences are found for RyRs expression during cochlear development. In the PND 1 and 5 groups, Corti's organ was structurally immature, morphological charac-

Table 2. Location of RyR expression in present study.

\begin{tabular}{|c|c|c|c|c|}
\hline & PND 1 & PND 10 & PND 14 & Adult \\
\hline Kolliker's organ & $\begin{array}{l}\text { Low expression in the } \\
\text { basilar part }\end{array}$ & Degeneration & & \\
\hline $\mathrm{OHCS}$ & $\begin{array}{l}\text { Immature and no } \\
\text { obvious expression }\end{array}$ & $\begin{array}{l}\text { Obscure } \\
\text { expression }\end{array}$ & \multicolumn{2}{|l|}{$\begin{array}{l}\text { Strong expression in the } \\
\text { infranuclear region and lower in } \\
\text { the supranuclear region }\end{array}$} \\
\hline IHCS & & & \multicolumn{2}{|l|}{$\begin{array}{l}\text { Wide expression, especially in } \\
\text { regions under the nuclei and near } \\
\text { the cell membrane }\end{array}$} \\
\hline $\begin{array}{l}\text { Supporting } \\
\text { cells }\end{array}$ & & & \multicolumn{2}{|l|}{$\begin{array}{l}\text { Strong expression in most kinds } \\
\text { of supporting cells' cytoplasm }\end{array}$} \\
\hline SGNs & \multicolumn{2}{|c|}{ Strong and wide expression in the cytoplasm } & \multicolumn{2}{|c|}{ Concentrated expression near cell membran } \\
\hline
\end{tabular}



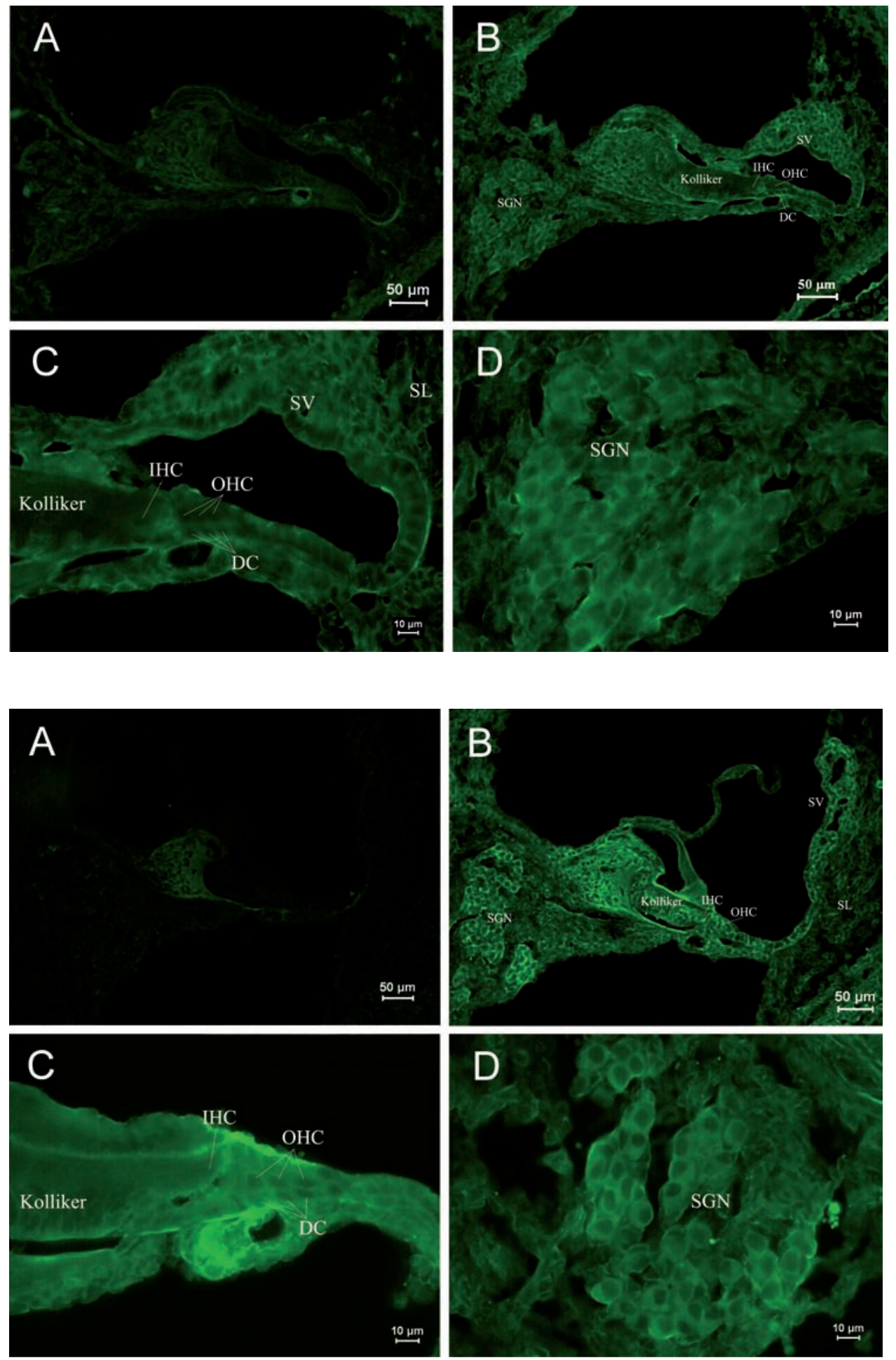

Figure 1. Immunostaining of RyRs in cochleae of the PND 1 group. (A) $\times 250$. Negative control. Non-specific staining could be seen at the edge of the spiral lamina and the outer lateral wall of the cochlea. (B) $\times \mathbf{1 0 0 0}$. Positive staining of RyRs was found in SGNs and stria vascularis. Slight staining was observed in the basilar Kolliker's organ. (C) $\times 400$.

Naive cells were found in Corti's organ. The expression of RyRs was not significant. Arrangement of IHCs and OHCs was found to be indistinct. (D) $\times 400$. SGNs were in clusters. Strong RyR expression was found in the cell body. (IHC: inner hair cell, OHC: outer hair cell, DC: Deiters cell, SGN: spiral ganglia neuron, SV: stria vascularis, SL: spiral ligament).

Figure 2. Immunostaining of RyRs in cochleae of the PND 5 group. (A) $\times 100$. Negative control. Non-specific staining could be seen at the edge of the spiral lamina. (B) $\times 100$. Positive staining of RyRs was found in SGNs and stria vascularis. The staining of Corti's organ was not significant. Positive staining of RyRs could be seen in Kolliker's organ. (C) $\times 400$. Naïve IHCs and OHCs were uniformly stained. Low expression of RyRs was found in the basilar Kolliker's organ. (D) $\times 400$. The staining of SGNs was similar to the PND 1 group. teristics of hair cells and supporting cells were not distinguished, and no significant expression of RyRs was observed (Figure $1 \mathrm{C}$ and $2 \mathrm{C}$ ). In the PND 10 group, the formation of Corti's organ was basically complete, and intracellular RyR expres- sion was dispersive (Figure $3 \mathrm{C}$ ). In the PND 14 group, Corti's organ was nearly mature, and the expression of RyRs showed a specific spatial distribution (Figure 4C). RyRs were widely expressed in IHCs, especially in the infranuclear region. In 

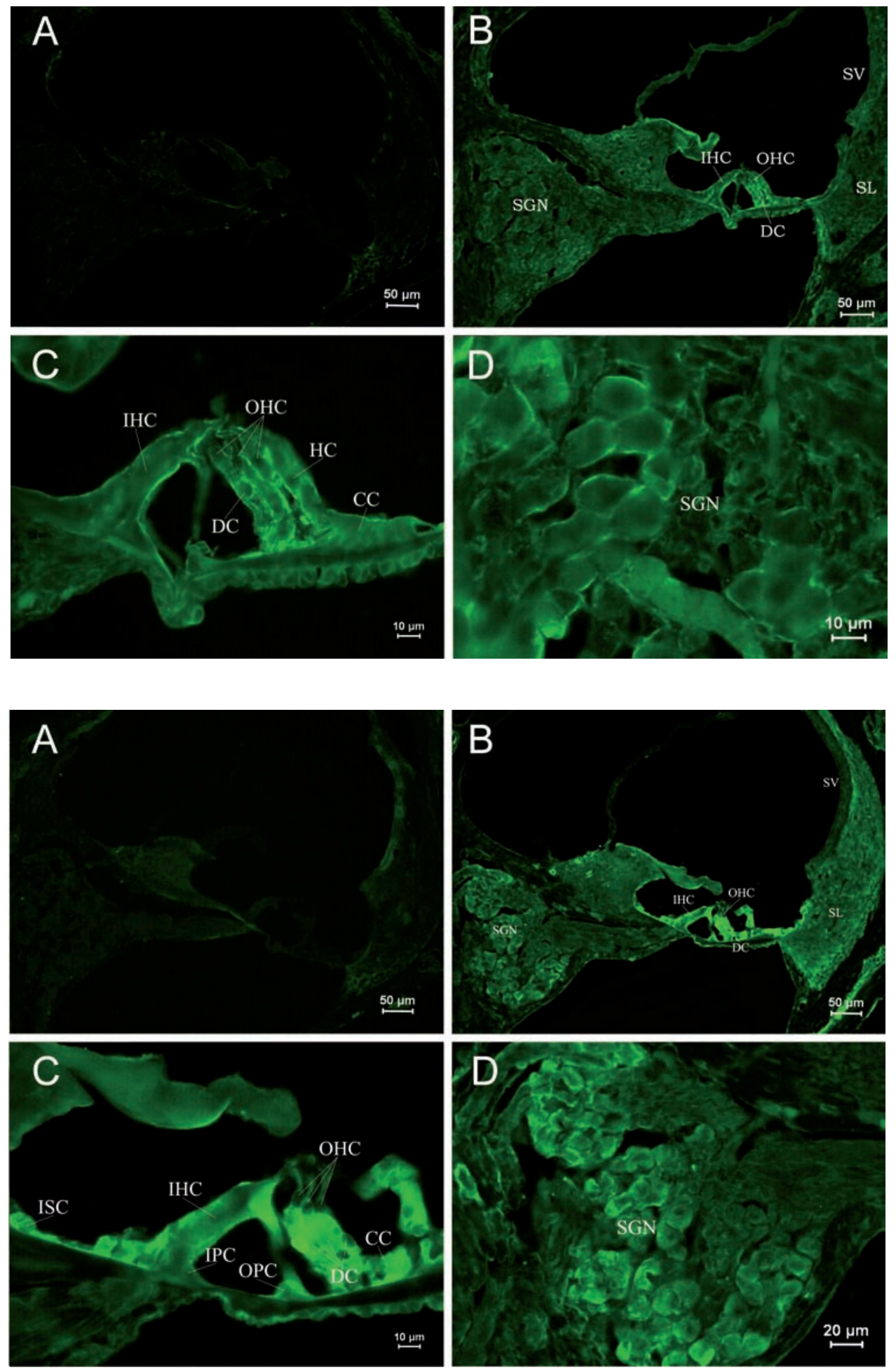

Figure 3. Immunostain of RyRs in cochleae of the PND 10 group. (A) $\times 100$. Negative control. Non-specific staining at the edge of the spiral lamina was weak. (B). $\times 100$. The formation of the cochlea was basically complete. Kolliker's organ was completely degraded. RyR expression was strong in Corti's organ and SGNs. (C) $\times 400$. Cells in Corti's organ were mature. Cell arrangement was tense. IHCs, OHCs, and supporting cells were uniformly stained. (D) $\times 400$. The staining of SGNs was similar to the PND 1 and 5 groups, but cells were not arranged in clusters. The cells were developmentally mature.
Figure 4. Immunostaining of RyRs in cochleae of the PND 14 group. (A) $\times 100$. Negative control. (B) $\times 100$. Cochleae were structurally fully developed. The strongest expression of RyRs was found in Corti's organ and second strongest was in SGNs. In stria vascularis, low expression was found in basilar cells. (C) $\times 400$. The differentiation of Corti's organ was close to that of an adult. RyRs were widely expressed in IHCs and concentrated in the region under the nuclei. Strong expression of RyRs was found in the region under the nuclei of OHCs and supporting cells, including Deiters' cells, Hensen cells, Claudius' cells, pillar cells, and inner sulcus cells. (D) $\times 200$. The intercellular space of SGNs became large. Significant expression of RyRs was found in the plasma.
$\mathrm{OHCs}$, immunofluorescence labeling can be found in the infranuclear region. The expression level was lower in the supranuclear region of $\mathrm{OHCs}$. RyRs were strongly expressed in Deiters' cell, Hensen cell, Claudius' cell, and the inner and outer pillar cells. The expression of RyRs at PND 28 was similar to that at PND 14 (Figure 5C). RyRs were strongly expressed in IHCs, especially in regions under the nuclei and near the cell membrane. RyRs were also strongly expressed in the 

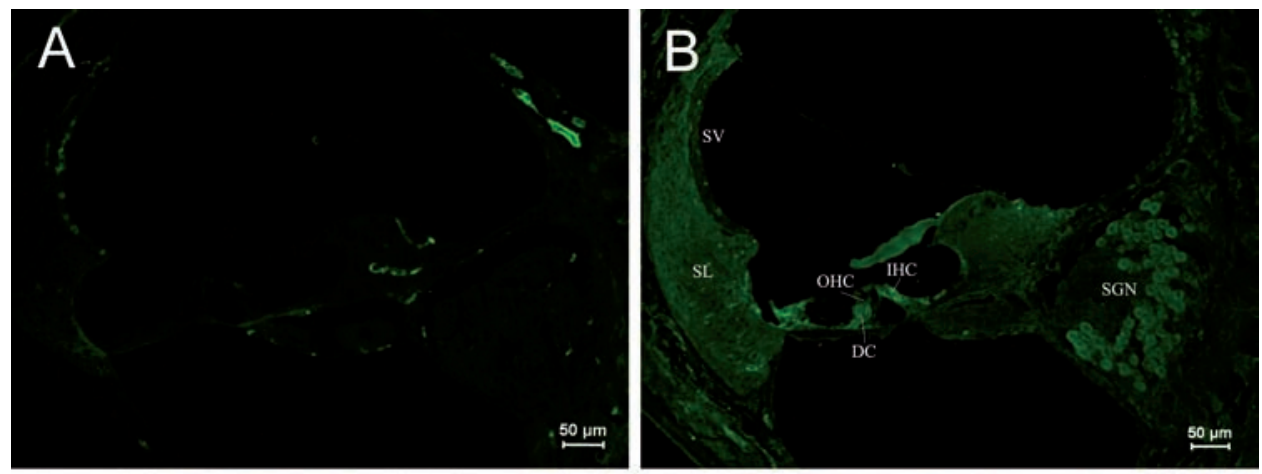

Figure 5. Immunostaining of RyRs in cochleae of the PND 28 group. (A) $\times 100$. Negative control. (B) $\times \mathbf{1 0 0}$. Structure of mature cochleae. Strong expression of RyRs was observed in Corti's organ and SGNs. (C) $\times 400$. Corti's organ was structurally mature. RyR was strongly expressed in the plasma of IHCs, especially under nuclei and near the membrane. (D) $\times 400$. RyR expression in SGNs. RyRs were concentrated near the cell mem-
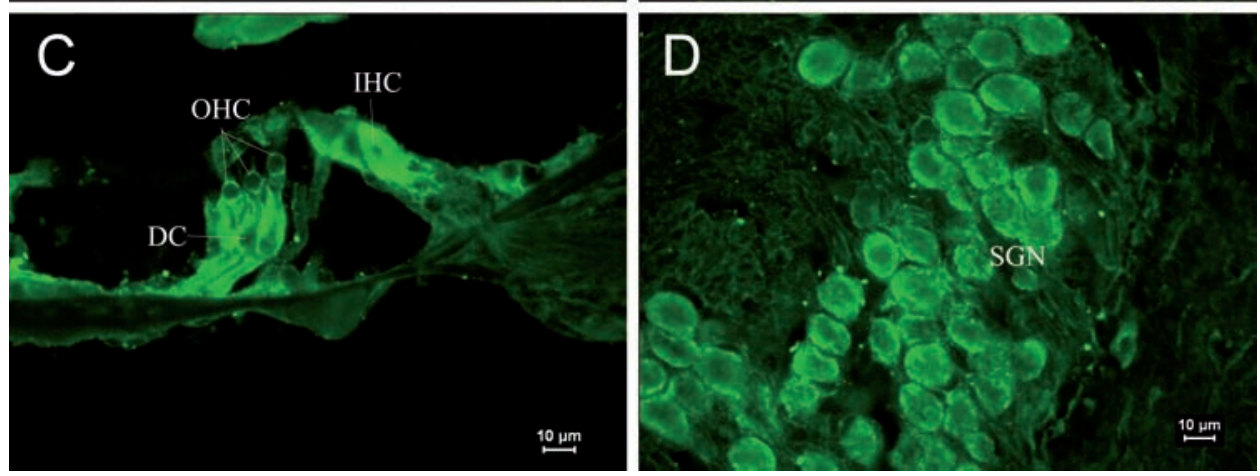
brane.
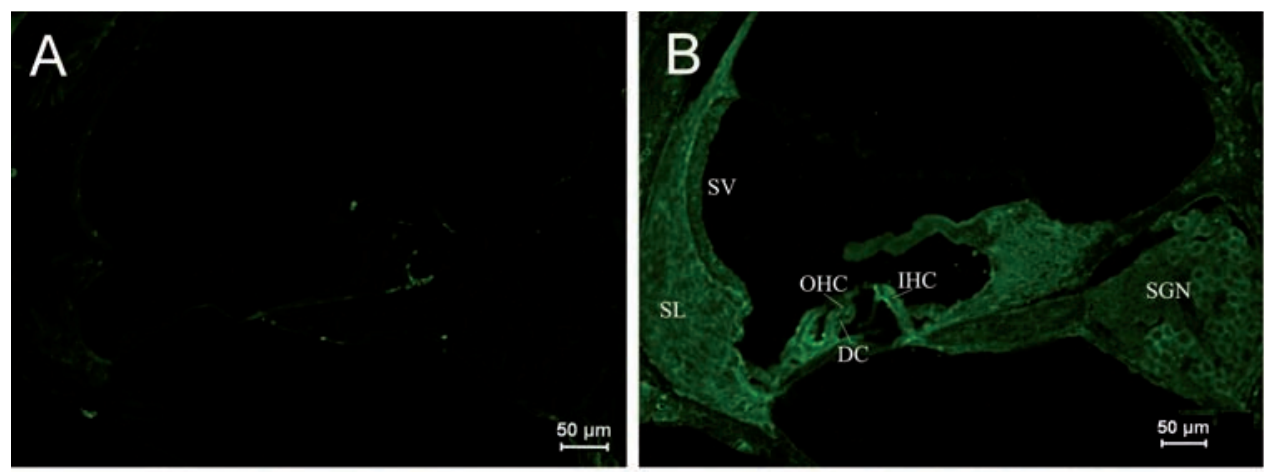

Figure 6. Immunostaining of RyRs in cochleae of the adult group. (A) $\times \mathbf{1 0 0}$. Negative control. (B) $\times 100$. RyRs were mainly expressed in Corti's organ. RyR staining was not complete in the plasma of SGNs. (C) $\times 400$. The expression of RyRs was uniform in IHCs and slightly stronger at the lateral wall. The expression of RyRs was significant under the reticular lamina of OHCs and a little lower above the nuclei. (D) $\times 400$. RyRs were expressed near the SGN mem-
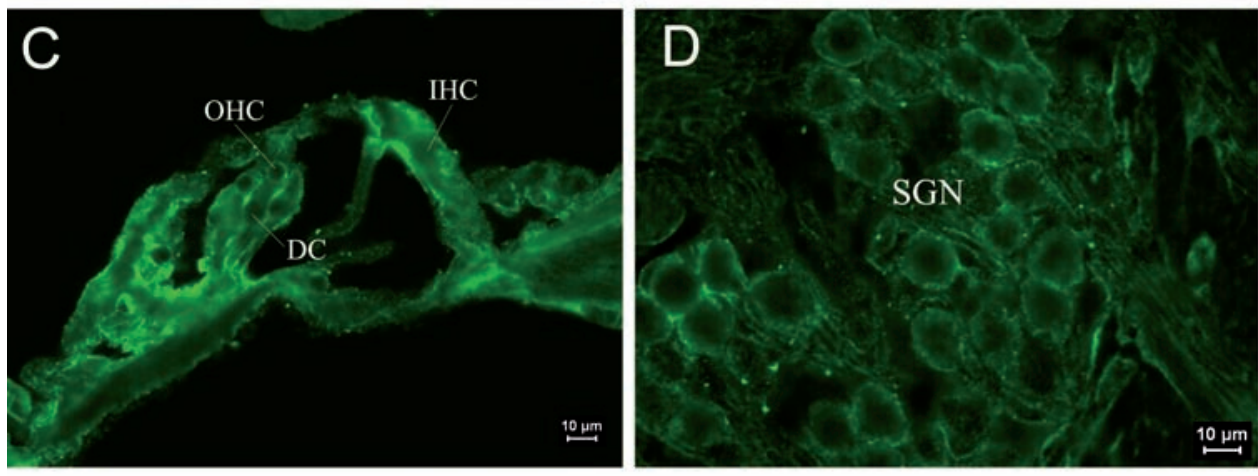

branes and were concentrated granularly in some areas.

region under the nuclei of $\mathrm{OHCs}$ and in supporting cells. In the adult group, RyRs were widely expressed in IHCs, and strongly expressed in the region under the nuclei of $\mathrm{OHCs}$ and in supporting cells (Figure $6 \mathrm{C}$ ). In younger age groups (PND 1 to 5) the number of SGNs was large, and cells were closely arranged in a cluster (Figure $1 \mathrm{~B}$ and 1D). In older age groups (PND 10 to 14), the number of SGNs decreased slightly, and although cells were still densely arranged, the number of 
cell clusters decreased (Figure 3B and 3D). In the PND 28 and adult groups, the number of SGNS was significantly decreased, and the intercellular space grew wider (Figure 5B and 5D). Ry Rs started to be expressed in SGNs in newborn animals, and the pattern of expression changed from wide and uniform to more localized concentrations. In the PND 28 and adult groups, RyRs were significantly concentrated near cell membrane (Figure $5 \mathrm{D}$ and 6D). In other parts of the cochlea, the stria vascularis was not completely developed, and the three cell layers were not significantly differentiated in the PND 1 and 5 groups. High expression of RyRs was found in the stria vascularis (Figures $1 \mathrm{~B}$ and 2B). In the PND 10 group, the development of the stria vascularis was nearly mature, and expression of RyRs was weaker than in younger age groups (Figure 3B). No significant expression of RyRs was found in the stria vascularis of the other three groups, and only weak expression was found in basilar cells. In the PND 14,28 , and adult groups, strong expression of RyRs was found in inner sulcus cells, and wide expression was observed in the spiral ligament (Figures 4B, 5B and 6B). Strong non-specific staining was observed at the edge of the spiral lamina, particularly at PND 5 (Figure 2A).

\section{Effects of ACh on $\left[\mathrm{Ca}^{2+}\right]_{i}$ in $\mathrm{OHCs}$}

In the presence of calcium (Hank's solution), the application of $100 \mu \mathrm{M} \mathrm{ACh}$ (the first group) caused a fast elevation of $\left[\mathrm{Ca}^{2+}\right]_{i}$, and the peak of relative fluorescence intensity was $1.430 \pm 0.010$ $U(n=5$, Figure $7 A)$. In the second group, fifty sec-

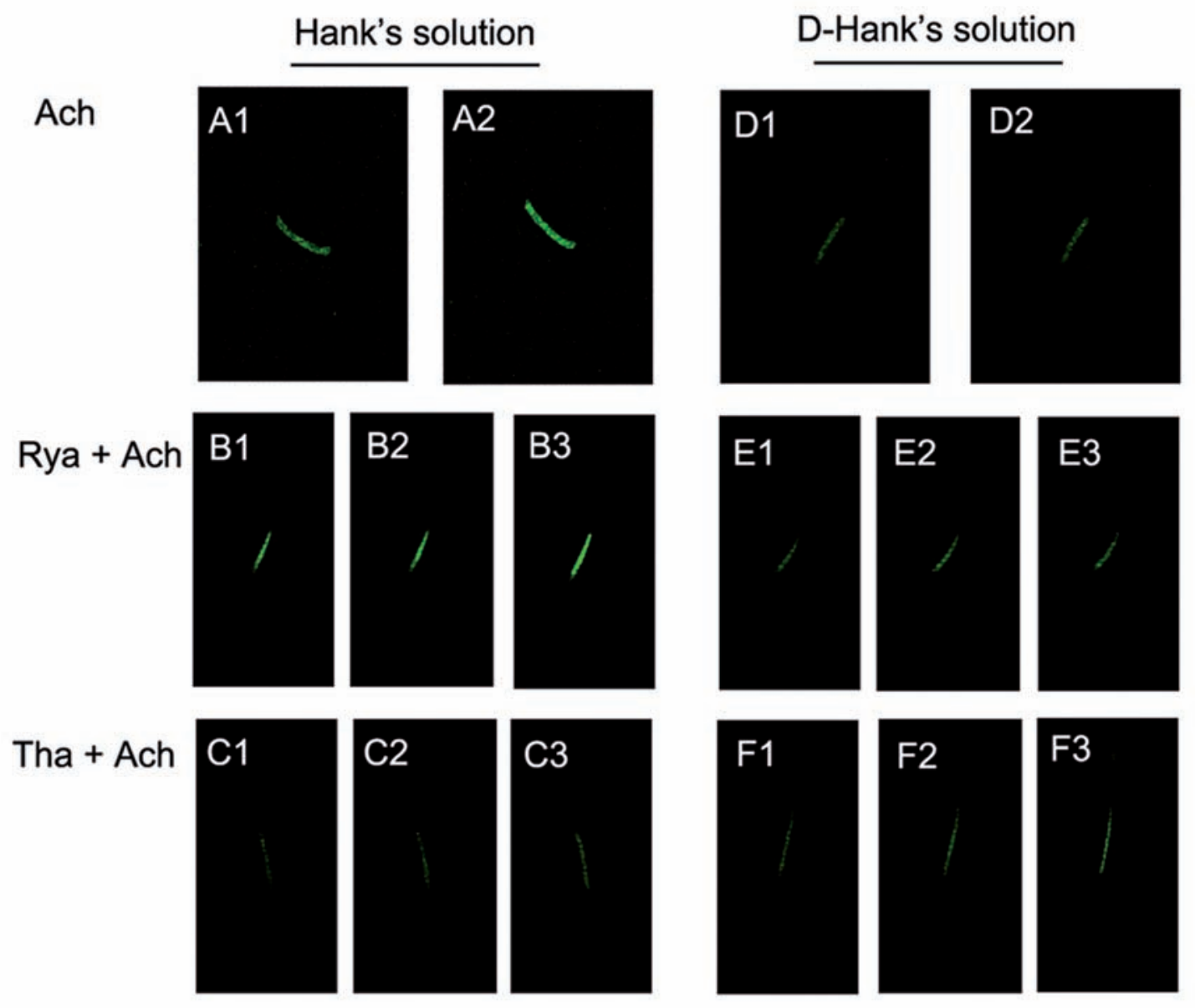

Figure 7. (A1-A2) Effects of $100 \mu \mathrm{M}$ ACh on the relative fluorescence intensity of OHC [Ca $\left.{ }^{2+}\right]$ in Hank's solution. (B1-B3) Effects of

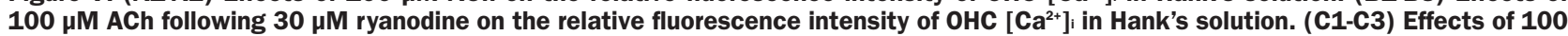
$\mu \mathrm{M}$ ACh following $30 \mathrm{nM}$ thapsigargin on the relative fluorescence intensity of $0 \mathrm{HC}^{\text {[Ca }}{ }^{2+}$ ] in Hank's solution. (D1-D2) Effects of 100 $\mu \mathrm{M}$ ACh on the relative fluorescence intensity of OHC [Ca $\left.{ }^{2+}\right] \mathrm{i}$ in D-Hank's solution. (E1-E3) Effects of $100 \mu \mathrm{M}$ ACh following $30 \mu \mathrm{M}$ ryanodine on the relative fluorescence intensity of $\mathrm{OHC}\left[\mathrm{Ca}^{2+}\right] \mathrm{i}$ in D-Hank's solution. (F1-F3) Effects of $100 \mu \mathrm{M}$ ACh following $30 \mathrm{nM}$ thapsigargin on the relative fluorescence intensity of $\mathrm{OHC}\left[\mathrm{Ca}^{2+}\right] \mathrm{i}$ in D-Hank's solution. 
onds after the experiment started, $30 \mu \mathrm{M}$ ryanodine was applied, and a gradual elevation of $\left[\mathrm{Ca}^{2+}\right]_{i}$ was observed in the $0 \mathrm{HCs}$. The relative fluorescence intensity increased from $1.000 \mathrm{U}$ in the resting condition to $1.140 \pm 0.0004 \mathrm{U}(n=5)$. The application of $100 \mu \mathrm{M}$ ACh at 220 seconds after the experiment started induced an immediate increase of $\left[\mathrm{Ca}^{2+}\right]_{i}$. The peak fluorescence intensity was $1.580 \pm 0.020 \mathrm{U}(n=5)$. After approximately 10 seconds, the $\left[\mathrm{Ca}^{2+}\right]_{i}$ returned to the resting level and did not change for 200 seconds. The final relative fluorescence intensity was $1.140 \pm 0.002 \cup(n=5$, Figure 7B). In the third group, fifty seconds after the experiment started, $30 \mathrm{nM}$ thapsigargin was applied and induced an increase of $\left[\mathrm{Ca}^{2+}\right]_{i}$, however, no significant peak was found. After 200 seconds of observation, the relative fluorescence intensity increased to $1.145 \pm 0.002 \cup(n=5)$.

The application of $100 \mu \mathrm{M}$ ACh after $250 \mathrm{sec}-$ onds induced a fast elevation of $\left[\mathrm{Ca}^{2+}\right]_{\text {, }}$, which reached a peak after 5 seconds and returned to the resting condition after 8 seconds. In the following 200 seconds, the relative fluorescence intensity slowly increased. The peak relative fluorescence intensity was $1.398 \pm 0.003 \mathrm{U}(n=5)$, and the final relative fluorescence intensity was 1.210 $0.010 \mathrm{U}(\mathrm{n}=5$, Figure $7 C)$. In calcium-free external solution (D-Hank's solution), the application of $100 \mu \mathrm{M}$ ACh (the fourth group) had no effect on $\mathrm{OHCs}$. The relative fluorescence intensity was $1.003 \pm 0.022 \cup(n=5$, Figure 7D). In the fifth group, fifty seconds after the experiment started, $30 \mu \mathrm{M}$ ryanodine was applied and a slow elevation of $\left[\mathrm{Ca}^{2+}\right]_{i}$ was observed in $\mathrm{OHCs}$. The relative fluorescence intensity increased to $1.1395 \pm 0.0006 \mathrm{U}$ $(n=5)$. ACh was applied 220 seconds after the start of the experiment, and the $\left[\mathrm{Ca}^{2+}\right]_{i}$ increased

Table 3. The relative fluorescence intensity in 6 groups.

\begin{tabular}{llll}
\hline Solution & $\begin{array}{l}\text { Only ACh } \\
\text { group }\end{array}$ & $\begin{array}{l}\text { Ryanodine }+A C h \\
\text { group }\end{array}$ & $\begin{array}{c}\text { Thapsigargin }+A C h \\
\text { group }\end{array}$ \\
\hline Hank's solution & $1.430 \pm 0.010 \mathrm{U}$ & $\begin{array}{l}1.140 \pm 0.0004 \mathrm{U} \\
1.580 \pm 0.020 \mathrm{U} *\end{array}$ & $\begin{array}{l}1.145 \pm 0.002 \mathrm{U} \\
\end{array}$ \\
D-Hank's solution & $1.003 \pm .022 \mathrm{U}$ & $1.1398 \pm 0.003 \mathrm{U} * *$ \\
& & $1.140 \pm 0.001 \mathrm{U} \#$ & $1.141 \pm 0.001 \mathrm{U}$ \\
& &
\end{tabular}

a) Before the application, the resting fluorescence intensity in each group was $1 U$; b) Except only ACh group in D-Hank's solution, the relative fluorescence intensity in all the other groups had statistical significance after application $(p<0.05) ;{ }^{*} p<0.05$ for Ryanodine+ACh group VS ACh group (Hank's solution); ${ }^{* *} p<0.05$ for Thapsigargin+ACh group VS ACh group (Hank's solution); $\# p<0.05$ for Ryanodine $+A C h$ group VS ACh group ( $D$ Hank's solution); \#\# $p<0.05$ for Thapsigargin $+A C h$ group VS ACh group (D-Hank's solution). slowly. The final relative fluorescence intensity was $1.140 \pm 0.001 \mathrm{U}(n=5$, Figure 7E). In the sixth group, fifty seconds after the experiment started, $30 \mathrm{nM}$ thapsigargin was applied, and $\left[\mathrm{Ca}^{2+}\right]_{\mathrm{i}}$ was found to increase. The relative fluorescence intensity increased to $1.141 \pm 0.001 \mathrm{U}(n=5)$ after 220 seconds. One-hundred $\mu \mathrm{M}$ ACh was then applied, and a slow elevation of fluorescence was observed. The final relative fluorescence intensity was $1.210 \pm 0.010 \mathrm{U}(n=5$, Figure $7 F)$. All values were described in Table 3.

\section{Discussion}

Recent studies found that RyR-mediated CICR was involved in many physiological processes in the cochlea. Strong expression of RyRs in IHCs, $\mathrm{OHCs}, \mathrm{SGNs}$, and supporting cells indicated that RyRs were involved in many physiological processes in cochleae, including release of afferent neurotransmitters from IHCs, cholinergic efferent responses of $\mathrm{OHCs}$, auditory encoding and transduction of SGNs, and non-sensory cell regulation of the electrochemical equilibrium of the cochlea (Beurg et al., 2005; Grant et al., 2006; Lioudyno et al., 2004; Morton-Jones et al., 2008; MortonJones et al., 2006). The morphological structures of developing rat cochleae at multiple stages of development are different. Therefore, we hypothesized that expression of RyRs is involved in the development of rat cochleae.

\section{RyR expression in different parts of cochleae during development}

\section{Differential expression of RyRs in IHCs}

In the auditory transduction, mechanical stimulus caused the displacement of stereocilium of hair cell in cochlea, then mechano-electrical transduction (m-e. t.) channel opened and nonspecific cation influx from extracellular, which caused depolarization of hair cell and formed the receptor potential. The receptor potential triggered the opening of L-type voltage-gated calcium channel (VGCC) and induced the calcium influx, and then $\mathrm{CICR}$ was triggered. $\mathrm{Ca}^{2+}$, as a second messenger, could induce series of actions of IHCs, such as regulation on activity of $\mathrm{Ca}^{2+}$-dependent potassium channel, release of $\mathrm{Ca}^{2+}$-dependent neurotransmitters. $\mathrm{Ca}^{2+}$ controlled the release of neu- 
rotransmitters in afferent synapsis of IHCs, which is the basic process that sound was transformed into excitation of auditory nerve (Beutner et al., 2001; Zhang et al., 1999). In present experiments, we found that RyR expression in IHCs increased as rats aged, and was mature after PND 14. As the PND increased, the distribution of RyRs became more concentrated, especially in the reticular laminae, lateral cell wall, and synaptic area. RyRs were strongly expressed in reticular laminae and lateral cell wall, where BK channel also highly expressed (Langer et al., 2003; Skinner et al., 2003). According to this, some researchers believe that coupling RyR-BK channels could inhibit the fast neurotransmission of IHCs (Beurg et al., 2005; Grant et al., 2006). Beurg et al. (2005) reported that ryanodine could reduce the repolarization current of $\mathrm{BK}$ channel and slightly shifted the membrane potential of $\mathrm{OHCs}$ to the depolarized direction of activating threshold of calcium channels (Beurg et al., 2005). RyR-mediated CICR could activate local BK channel, induce fast hyperpolarization and inhibit the action of synapses. RyRs were believed to control the release of neurotransmitters by affecting BK channel and membrane potential (Beurg et al., 2005). The release of neurotransmitters were triggered by VGCCs, and CICR mainly regulated $B K$ channels of IHCS, which inhibited neural transmission in the extreme condition of calcium accumulation, such as overstimulation of sound or local ischemia, acting like a emergency brake. High expression of RyRs in afferent synapses suggested that CICR could regulate not only the release of neurotransmitters but also the transportation of vesicles (Furukawa, 1986). Kennedy et al (2002) investigated presynaptic depolarization-induced calcium influx in IHCs of mice using confocal microscopy, and provided the proof of presynaptic existence of CICR in IHCs where increase of calcium concentration in basal part of cell could promote the release of afferent neurotransmitter to the terminal (Kennedy and Meech, 2002). RyRs expression in PND 28 group was similar to PND 14 group, and strong expression of RyR was found in synaptic area under nucleus. RyRs expression in adult group was also concentrated in reticular laminae, lateral cell wall and synaptic area. The expression patterns of RyRs found in this study provided a molecular basis of CICR in IHCs.

\section{Differential expression of RyRs in OHCS}

Similar to IHCs, the expression of RyRs in OHCs also increased with development, and was mature after PND 14. Strong expression of RyRs was found under the nuclei of OHCs. This area was the location of synaptoplasmic cistern. The distance between postsynaptic membrane and it was only $30 \mathrm{~nm}$. Calcium influx was induce when acetylcholine affected at postsynaptic membrane, and then induced CICR. Since synaptoplasmic cistern was close to cell membrane and might be connected with the membrane, it could effectively inhibit the efferent transmission. Acetylcholine could induce calcium influx via affecting nicotinic receptor and activate calcium-dependent potassium channel. Ryanodine and other calcium store activators could alter the level of transient ion flow of $\mathrm{OHC}$ caused by endogenous and exogenous acetylcholine. In the mechanism of smooth muscular excitation-contraction coupling, RyRs in ER coupling with VGCC mediated the process of CICR. Both endogenous and exogenous acetylcholine-induced current could be promoted by intracellular calcium store activator, which might be closely related with synaptoplasmic cistern (Evans et al., 2000).

Differential expression of RyRs in supporting cells

Kolliker's organ was not completely degraded in rat cochleae of the PND 1 and 5 groups, and Corti's organ was at an early stage of development. RyRs started to be expressed in Kolliker's organ in the PND 5 group, which might be involved in the following degradation and apoptosis, as it was reported that endoplasmic reticulum induced apoptosis was closely related to $\mathrm{Ca}^{2+}$ (Verkhratsky and Petersen, 2002). In addition, Kolliker's organ was an important structure which could release ATP in postnatal early period of cochlea development (Tritsch et al., 2007). Though it was not clear whether ATP vesicles existed in supporting cells of Kolliker's organ, but it was reported that ATP was released in vesicle form generally (White et al., 1995), and $\mathrm{Ca}^{2+}$ could promote the transportation and/or release of vesicles. Therefore, it suggested that RyRs might be involved in the release of ATP. No significant expression of RyRs was observed in the PND 1 and 5 groups since Corti's organ was not completely formed. Weak expression of RyRs was found in the PND 10 group. Strong expression was found in the apical and basilar parts of the outer pillar cell, Deiters cell, and Hensen cell in the 
PND 14 group.

In the PND 28 and adult groups, the expression of RyRs was strong in supporting cells. It was previously reported that supporting cells were one of the sources of ATP (Zhao et al., 2005). Intracellular free calcium could change the mechanical response of Deiters cell (Bobbin, 2001). RyR-mediated CICR was involved in regulating the gap junction of supporting cells (Sato et al., 1998). A previous study reported that ATP could be released from damaged hair cells induced by noise and triggers the calcium wave spread in supporting cells (Gale et al., 2004). RyR-mediated CICR might also be involved in this process.

\section{Differential expression of RyRs in SGNs}

RyR expression has been shown in neural tissues (Bardo et al., 2006; Verkhratsky and Petersen, 2002). In current study, the spiral neurons were strongly expressed in all different age cochlear tissues of rats.

During maturation of cochleae and development of SGNs, the expression changed from wide expression in the cytoplasm (PND 1 to 14 ) to local expression near the membrane region (PND 28 and adult). In the SGNs of adult rats, RyRs were expressed granularly near the cell membrane, which indicated that RyRs were involved in the regulation of membrane conductance and resting potential of SGNs and probably affected the encoding and transduction of auditory information (Skinner et al., 2003). We found that during the postnatal development of rat cochlea, the formation of SGNs matured, the intercellular space turned big and the total number of cells decreased, therefore, we believed that the maturation of SGNs was a process of apoptosis. Previous studies found that some drugs could promote or inhibit apoptosis by interfering calcium channels on the ER membrane then altering calcium concentration in ER (Verkhratsky and Petersen, 2002). Change in intracellular calcium concentration might induce ER stress, and excessive ER stress resulted in cell apoptosis. Since ER and mitochondria were spatially close to each other, calcium released from ER could trigger mitochondria-induced apoptosis. ER and mitochondria were functionally connected in the process of cell apoptosis and $\mathrm{Ca}^{2+}$ was an important signal molecular in this connection (Walter and Hajnoczky, 2005). $\mathrm{Ca}^{2+}$ released from ER into plasma via IP3R or RyR could also increase the calcium concentration in mitochondria. Some drug such as ceramide could induce calcium release from ER of Hela cells and calcium overload in mitochondria, and cause mitochondria swelling and destruction, then resulted in cell apoptosis (Rizzuto et al., 2003). Pan et al (2000) reported that caffeine and ryanodine could trigger the depletion of calcium in ER and resulted in the apoptosis of ovarian cell in Chinese hamster (Pan et al., 2000). According to these studies, we concluded that wide expression of RyRs in SGNs of low age group might be involved in apoptosis during the postnatal development of SGNs. Nerve fibers were reported to induce the differentiation and maturation of sensory hair cells and supporting cells (Kelley, 2006). We found that RyRs expressed in SGNs earlier than in hair cells and supporting cells, which suggested nerve fiber induced the differentiation and maturation of sensory hair cells and supporting cells by releasing certain neurotransmitter that might be ATP since RyR-mediated CICR was involved in neurotransmitter release and SGNs might be one of the ATP source in cochlea.

Differential expression of RyRs in stria vascularis During development of the cochlea lateral wall, RyR expression was observed in naïve stria vascularis cells at PND 1 to 5. In the following period, RyR expression was only found in basilar cells of the stria vascularis. The function of RyRs in stria vascularis cells was not clear. Basilar cell of stria vascularis was secretory cell that could secret $\mathrm{K}^{+}$. Whether CICR was involved in the transportation of $\mathrm{K}^{+}$need further study.

\section{ACh might induce CICR in OHCs of rat cochleae}

Acetylcholine receptors (AChRs) in hair cells are ligand-gated ion channels that could hyperpolarize hair cells and inhibit their action. Unique postsynaptic signaling at the hair cell efferent synapse permits calcium to evoke changes on two time scales. Sridhar et al (1997) found two temporal phases of cholinergic efferent inhibition in mammalian OHCs (Sridhar et al., 1997). In the fast phase, calcium influx via nicotinic receptor channels induced the opening of the calciumdependent potassium channel. In the slow phase, calcium influx induced CICR and caused calcium release from the $\mathrm{OHC}$ calcium store. The role of 
the fast phase was to regulate the encoding of auditory signals in the cochlea, and the role of slow phase was to protect $\mathrm{OHCs}$ from auditory overstimulation.

To further investigate whether calcium elevation in OHCs induced by ACh could trigger CICR, we observed $\left[\mathrm{Ca}^{2+}\right]_{i}$ changes in OHCs by the application of $\mathrm{ACh}$, thapsigargin, and ryanodine in the presence of calcium or in calcium-free conditions. Thapsigargin could bind with ER ATPase and form an irreversible complex, and then inhibit $\mathrm{Ca}^{2+}$-ATPase selectively, resulted in the depletion of ER calcium store and the sustained elevation of $\left[\mathrm{Ca}^{2+}\right]_{i}$ (Bobbin, 2002). Ryanodine, an agonist of Ry $R$, can increase the activity of Ry $R$, reduce the activating threshold of CICR, and trigger the release of intracellular ryanodine-sensitive calcium store. Ryanodine acts as an agonist at low concentration $(\leq 50 \mu \mathrm{M})$ and an antagonist at high

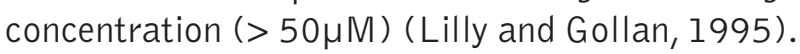
We found that the application of $100 \mu \mathrm{M} \mathrm{ACh}$ could induce a fast elevation of $\left[\mathrm{Ca}^{2+}\right]_{i}$ in $\mathrm{OHCs}$ in the presence of extracellular calcium and had no effect on $\left[\mathrm{Ca}^{2+}\right]_{i}$ in calcium-free external solutions, which indicated the effect of ACh was calciumdependent. Furthermore, we applied ryanodine or thapsigargin before ACh application in the presence of calcium or in calcium-free condition. When ryanodine was applied before ACh application in the presence of calcium, the elevation of $\left[\mathrm{Ca}^{2+}\right]_{i}$ was higher than that induced by $\mathrm{ACh}$ alone. A potential mechanism is that application of ryanodine reduced the activating threshold of the RyR, and the following application of ACh induced the CICR which contributed to the elevation of $\left[\mathrm{Ca}^{2+}\right]_{\text {i }}$. When thapsigargin was applied before $\mathrm{ACh}$, the elevation of $\left[\mathrm{Ca}^{2+}\right]_{i}$ was lower than that induced by ACh alone, which suggested that thapsigargin might cause an irreversible depletion of the IP3sensitive calcium store. Thus, the following ACh application was unable to trigger IP3-sensitive calcium release, and the total $\left[\mathrm{Ca}^{2+}\right]_{i}$ elevation was reduced. In calcium-free external solution, regardless of whether ryanodine or thapsigargin was applied first, the following ACh application had no effect on $\left[\mathrm{Ca}^{2+}\right]_{i}$, which further proved that the effects of ACh were calcium- dependent.

This study proved that ACh-induced calcium release was not only contributed by IP3-sensitive calcium store, but also by ryanodine-sensitive calcium store. Previous reported slow elevation of $\left[\mathrm{Ca}^{2+}\right]_{i}$ might involve CICR. CICR could be triggered by both calcium influx via membrane calcium channel and by calcium release from IP3-sensitive calcium store. With or without extracellular calcium, IP3sensitive calcium store can co-operated with ryanodine-sensitive calcium store and precisely regulate the intracellular calcium concentration.

These results suggested that $\mathrm{ACh}$-induced calcium release was contributed to a combination of the IP3-sensitive calcium store and the ryanodinesensitive calcium store in $\mathrm{OHCs}$ of rat cochleae.

\section{Acknowledgements}

This investigation was supported by the National Natural Science Foundation of China (NSFC), grant no. 30772396.

\section{References}

Auestad N, Stockard-Sullivan J, Innis SM, Korsak R, Edmond J. Auditory brainstem evoked response in juvenile rats fed rat milk formulas with high docosahexaenoic acid. Nutr Neurosci 2003;6:33541.

Bardo S, Cavazzini MG, Emptage N. The role of the endoplasmic reticulum $\mathrm{Ca} 2+$ store in the plasticity of central neurons. Trends Pharmacol Sci 2006;27:78-84.

Beurg M, Hafidi A, Skinner LJ, Ruel J, Nouvian R, Henaff M, et al. Ryanodine receptors and $\mathrm{BK}$ channels act as a presynaptic depressor of neurotransmission in cochlear inner hair cells. Eur J Neurosci 2005; 22:1109-19.

Beutner D, Voets T, Neher E, Moser T. Calcium dependence of exocytosis and endocytosis at the cochlear inner hair cell afferent synapse. Neuron 2001; 29:681-90.

Blanchet C, Eróstegui C, Sugasawa M, Dulon D. Acetylcholine-induced potassium current of guinea pig outer hair cells: its dependence on a calcium influx through nicotinic-like receptors. J Neurosci 1996; 16:2574-84

Bobbin RP. ATP-induced movement of the stalks of isolated cochlear Deiters' cells. Neuroreport 2001;12:2923-6.

Bobbin RP. Caffeine and ryanodine demonstrate a role for the ryanodine receptor in the organ of Corti. Hear Res 2002;174:172-82.

Brandt N, Kuhn S, Munkner S, Braig C, Winter H, Blin N, et al. Thyroid hormone deficiency affects postnatal spiking activity and expression of $\mathrm{Ca} 2+$ and $\mathrm{K}+$ channels in rodent inner hair cells. J Neurosci 2007;27:3174-86

Chakraborti S, Das S, Kar P, Ghosh B, Samanta K, Kolley S, et al. Calcium signaling phenomena in heart diseases: a perspective. Mol Cell Biochem 2007;298:1-40.

Evans MG, Lagostena L, Darbon P, Mammano F. Cholinergic control of membrane conductance and intracellular free $\mathrm{Ca} 2+$ in outer hair cells of the guinea pig cochlea. Cell Calcium 2000;28:195-203.

Fabiato A. Calcium-induced release of calcium from the cardiac sarcoplasmic reticulum. Am J Physiol 1983;245:C1-14.

Furukawa T. Sound reception and synaptic transmission in goldfish hair cells. Jpn J Physiol 1986;36:1059-77.

Gale JE, Piazza V, Ciubotaru CD, Mammano F. A mechanism for sensing noise damage in the inner ear. Curr Biol 2004; 14:526-9.

Grant L, Slapnick S, Kennedy H, Hackney C. Ryanodine receptor localisation in the mammalian cochlea: an ultrastructural study. Hear Res 2006;219:101-9.

Jorgensen AO, Shen AC, Arnold W, McPherson PS, Campbell KP. The $\mathrm{Ca} 2+-$ release channel/ryanodine receptor is localized in junctional and corbular sarcoplasmic reticulum in cardiac muscle. J Cell Biol 1993;120:969-80. 
Kelley MW. Regulation of cell fate in the sensory epithelia of the inner ear. Nat Rev Neurosci 2006;7:837-49.

Kennedy $\mathrm{HJ}$, Meech RW. Fast $\mathrm{Ca}+$ signals at mouse inner hair cell synapse: a role for $\mathrm{Ca} 2+-$ induced $\mathrm{Ca} 2+$ release. J Physiol 2002;539:15-23.

Langer P, Grunder S, Rusch A. Expression of Ca2+-activated BK channel mRNA and its splice variants in the rat cochlea. J Comp Neurol 2003;455:198-209.

Lee JH, Heo JH, Kim CH, Chang SO, Kim CS, Oh SH. Changes in P2Y4 receptor expression in rat cochlear outer sulcus cells during development. Hear Res 2007;228:201-11.

Lilly LB, Gollan JL. Ryanodine-induced calcium release from hepatic microsomes and permeabilized hepatocytes. Am J Physio 1995;268:G1017-24.

Lioudyno M, Hiel H, Kong JH, Katz E, Waldman E, ParameshwaranIyer $\mathrm{S}$, et al. A "synaptoplasmic cistern" mediates rapid inhibition of cochlear hair cells. J Neurosci 2004;24:11160-4.

Marcotti W, Johnson SL, Kros CJ. Effects of intracellular stores and extracellular $\mathrm{Ca}(2+)$ on $\mathrm{Ca}(2+)$-activated $\mathrm{K}(+)$ currents in mature mouse inner hair cells. J Physiol 2004;557:613-33.

Morton-Jones RT, Cannell MB, Jeyakumar LH, Fleischer S, Housley $\mathrm{GD}$. Differential expression of ryanodine receptors in the rat cochlea. Neuroscience 2006;137:275-86.

Morton-Jones RT, Cannell MB, Housley GD. Ca2+ entry via AMPAtype glutamate receptors triggers $\mathrm{Ca} 2+$-induced $\mathrm{Ca} 2+$ release from ryanodine receptors in rat spiral ganglion neurons. Cell Calcium 2008;43:356-66.

Olivares EB, Tanksley SJ, Airey JA, Beck CF, Ouyang Y, Deerinck TJ, et al. Nonmammalian vertebrate skeletal muscles express two triad junctional foot protein isoforms. Biophys J 1991;59:1153-63.

Ouyang $Y$, Deerinck TJ, Walton PD, Airey JA, Sutko JL, Ellisman MH. Distribution of ryanodine receptors in the chicken central nervous system. Brain Res 1993;620:269-80.

Pan Z, Damron D, Nieminen AL, Bhat MB, Ma J. Depletion of intracellular $\mathrm{Ca} 2+$ by caffeine and ryanodine induces apoptosis of chinese hamster ovary cells transfected with ryanodine receptor. J Biol Chem 2000;275:19978-84.

Powers BE, Widholm JJ, Lasky RE, Schantz SL. Auditory deficits in rats exposed to an environmental PCB mixture during development. Toxicol Sci 2006;89:415-22.

Rizzuto R, Pinton P, Ferrari D, Chami M, Szabadkai G, Magalhaes PJ, et al. Calcium and apoptosis: facts and hypotheses. Oncogene 2003;22:8619-27.

Sato $Y$, Handa T, Matsumura M, Orita Y. Gap junction change in supporting cells of the organ of Corti with ryanodine and caffeine. Acta Otolaryngol 1998;118:821-5.

Skinner LJ, Enee V, Beurg M, Jung HH, Ryan AF, Hafidi A, et al. Contribution of $\mathrm{BK}$ Ca2+-activated $\mathrm{K}+$ channels to auditory neurotransmission in the Guinea pig cochlea. J Neurophysiol 2003; $90: 320-32$.

Sridhar TS, Brown MC, Sewell WF. Unique postsynaptic signaling at the hair cell efferent synapse permits calcium to evoke changes on two time scales. J Neurosci 1997;17:428-37.

Tritsch NX, Yi E, Gale JE, Glowatzki E, Bergles DE. The origin of spontaneous activity in the developing auditory system. Nature 2007;450:50-5.

Verkhratsky A, Petersen $\mathrm{OH}$. The endoplasmic reticulum as an integrating signalling organelle: from neuronal signalling to neuronal death. Eur J Pharmacol 2002;447:141-54.

Walter L, Hajnoczky G. Mitochondria and endoplasmic reticulum: the lethal interorganelle cross-talk. J Bioenerg Biomembr 2005;37:191-206.

Walton PD, Airey JA, Sutko JL, Beck CF, Mignery GA, Südhof TC, et al. Ryanodine and inositol trisphosphate receptors coexist in avian cerebellar Purkinje neurons. J Cell Biol 1991;113:1145-57.

White PN, Thorne PR, Housley GD, Mockett B, Billett TE, Burnstock $G$. Quinacrine staining of marginal cells in the stria vascularis of the guinea-pig cochlea: a possible source of extracellular ATP? Hear Res 1995;90:97-105.

Zhang SY, Robertson D, Yates G, Everett A. Role of L-type Ca(2+) channels in transmitter release from mammalian inner hair cells I. Gross sound-evoked potentials. J Neurophysiol 1999;82:3307-15.

Zhao HB, Yu N, Fleming CR. Gap junctional hemichannel-mediated ATP release and hearing controls in the inner ear. Proc Natl Acad Sci USA 2005; 102:18724-9. 